\title{
Reflexões Sobre Matemática e Verdade
}

\author{
Reflections on Mathematics and Truth
}

\author{
Valdir Damázio Júnior* \\ ORCID iD 0000-0003-0741-003X \\ Danielle Leitempergher Venson** \\ ORCID iD 0000-0002-9386-6377
}

\begin{abstract}
Resumo
O presente artigo busca discutir e problematizar a verdade dentro do contexto do conhecimento matemático e sua intrínseca relação com o desenvolvimento da ciência moderna e da modernidade. Para isso busca apresentar e discutir as ideias apresentadas por Michel Foucault sobre verdade-conhecimento e a noção de imaginário do ponto zero apresentada por Castro-Gómez. Após esta análise inicial, o artigo apresenta a noção de ideologia da certeza, que é uma das formas pelas quais as concepções de verdade apresentadas por Foucault e Castro-Gómez adentram no contexto escolar e da Educação Matemática. Por fim, apresentamos outro tipo de verdade, também proposta por Foucault e denominada verdade-acontecimento e sua relação com o contexto escolar.
\end{abstract}

Palavras-chave: Verdade-conhecimento. Imaginário do Ponto Zero. Ideologia da Certeza. Verdadeacontecimento. Educação Matemática.

\begin{abstract}
The article aims to discuss and problematize the truth in the mathematical knowledge context and its intrinsic relation with the development of modern science and the modernity period. In order to do so, we will present and discuss the concepts presented by Michel Foucault on truth-knowledge and the zero-point epistemology notion presented by Castro-Gómez. After this initial analysis, the article presents the certainty ideology notion, which is one of the ways in which this truth conception presented by Foucault and Castro-Gómez in Mathematics enters the school context and Mathematics Education. Finally, we present another kind of truth, also proposed by Foucault and called the 'truth-event' and its relation to the school context.
\end{abstract}

Keywords: Truth-knowledge. Zero-point epistemology. Certainty Ideology. Truth-even. Mathematics Education.

\section{A construção da noção de verdade}

\footnotetext{
* Mestre em Educação Científica e Tecnológica pela Universidade Federal de Santa Catarina (UFSC). Professor na Universidade do Estado de Santa Catarina (UDESC), Joinville, Santa Catarina, Brasil. Endereço para correspondência: Rua Paulo Malschitzki, 200, Zona Industrial Norte, Joinville, Santa Catarina, Brasil, CEP: 89219-710. E-mail: valdir.damazio@udesc.br.

** Licenciada em Matemática pela Universidade do Estado de Santa Catarina (UDESC). Professora de Matemática na Secretaria do Estado de Santa Catarina (SED), Joinville, Santa Catarina, Brasil. Endereço para correspondência: Rua Cidade de Pilões, s/n, bairro Santa Catarina, Joinville, Santa Catarina, Brasil, CEP:89233425. E-mail: daniellevenson@live.com.
} 
Falar sobre a construção da noção de verdade certamente não é uma tarefa fácil, principalmente pela complexidade e abrangência da mesma.

Para tanto, buscaremos nos ater apenas em alguns pontos. Mais precisamente, tentaremos abordar o que podemos chamar de verdade científica; a crença de que o discurso científico é neutro e verdadeiro; e de que esse pretende ser a forma mais pura e eficiente de se aproximar, através de seus métodos rigorosos, da verdade. É desta forma de conhecimento que consideramos ser a Matemática o melhor exemplo, bem como uma das principais engrenagens que possibilitaram a existência desse discurso. Assim ela é produto e, ao mesmo tempo, produtora desta maneira de ver e pensar o mundo.

O discurso científico a partir da modernidade valorizou de maneira cada vez mais intensiva o uso da razão como caminho seguro, infalível e único de atingir um conhecimento verdadeiro sobre o mundo, tanto físico como social.

Tal crença pode ser facilmente observada na obra Discurso do Método, publicada em 1637, pelo filósofo e matemático francês René Descartes. Nesta obra, Descartes considera que poucos preceitos racionais são considerados suficientes para se chegar a conclusões verdadeiras.

[...] em vez de grande número de preceitos de que se compõe a lógica, julguei que me seriam suficientes os quatro seguintes $[\ldots]$. O primeiro era o de jamais aceitar algo como verdadeiro sem saber com evidência que seja tal; isto é, evitar com cuidado a precipitação e a prevenção, e nada mais incluir em meus juízos além do que se apresente tão clara e tão distintamente ao meu espírito que eu não tenha nenhuma ocasião de pô-lo em dúvida. O segundo, o de dividir cada difículdade examinada em tantas partes quantas puder e for necessário para melhor resolvê-las. $\mathrm{O}$ terceiro, conduzir pela ordem os meus pensamentos, começando pelos objetos mais simples e mais fáceis de se conhecer, para subir aos poucos, como por degraus, até o conhecimento dos mais compostos e supondo até haver certa ordem entre os que não se precedem naturalmente uns aos outros. E o último, fazer em toda parte enumerações tão completas e revisões tão gerais, que me assegure de nada omitir (DESCARTES, 2009, p.25).

A certeza na infalibilidade de tal método, diretamente relacionado ao cogito cartesiano, em que, uma vez obtida a certeza da existência de um ser que pensa, este é capaz de chegar pela razão até qualquer saber, fica ainda mais evidente quando Descartes coloca que

Essas longas cadeias de razões, todas simples e fáceis, de que os geômetras costumam servir-se para chegar às mais difíceis demonstrações, me haviam dado a oportunidade de imaginar que todas as coisas podem cair sob o conhecimento dos homens se seguem umas às outras do mesmo modo e, contanto que nos abstenhamos de aceitar como verdadeira alguma que não o seja e sempre conservemos a ordem necessária para deduzi-las umas das outras, não pode haver nenhuma tão distante a que não cheguemos, nem tão escondida que não a descubramos (DESCARTES, 2009, p.26).

Essa ideia do cogito Cartesiano e a crença na obtenção de uma certeza por meio do 
emprego da razão fui duramente criticada pelo filósofo Friedrich Nietzsche.

\begin{abstract}
Ainda há ingênuos observadores de si mesmos que acreditam existir "certezas imediatas"; por exemplo "eu penso" [...]. Repetirei mil vezes, porém, que "certeza imediata", assim como "conhecimento absoluto" e "coisa em si", envolve uma contradictio in adjecto[...]: deveríamos nos livrar, de uma vez por todas, da sedução das palavras! Que o povo acredite que conhecer é conhecer até o fim; o filósofo tem que dizer a si mesmo: se decomponho o processo que está expresso na proposição "eu penso", obtenho uma série de afirmações temerárias, cuja fundamentação é difícil, talvez impossível [...] que eu sei o que é pensar. Pois se eu já não tivesse me decidido comigo a respeito, por qual medida julgaria que o que está acontecendo não é talvez "sentir", ou “querer"? (NIETZSCHE, 2005, p. 20-21).
\end{abstract}

Michel Foucault (2006), no curso O poder psiquiátrico, ministrado em 1974, discute sobre uma pequena história da verdade em geral. Neste curso, Foucault denomina e apresenta a verdade científica como verdade-conhecimento ou verdade-demonstração.

Para a ciência, a verdade não pode permanecer escondida, pois ela está sempre presente, a verdade está sempre aí. Se a verdade não se apresenta, é porque algumas limitações precisam ser superadas. Desta forma, se tivermos os instrumentos corretos para descobri-la, as categorias para pensá-la e a adequada linguagem para formulá-la, a verdade pode ser alcançada. A concepção filosófico-científica de verdade está ligada a uma tecnologia determinada de construção ou constatação como direito universal da verdade, uma tecnologia de demonstração (FOUCAULT, 2006, p. 302).

Para Nietzsche (1983), a verdade não passa de

Um batalhão móvel de metáforas, metonímias, antropomorfismos, enfim, uma soma de relações humanas, que foram enfatizadas poética e retoricamente, transpostas, enfeitadas, e que, após longo uso, parecem a um povo sólidas, canônicas e obrigatórias: as verdades são ilusões, das quais se esqueceu que o são, metáforas que se tornaram gastas e sem força sensível, moedas que perderam sua efígie e agora só entram em consideração como metal, não mais como moedas (NIETZSCHE, 1983, p. 48).

É sob o manto da neutralidade e de um método rigoroso que a verdade científica mascara o fato de que é apenas uma forma de saber dentre tantas outras. Por trás do discurso da verdade-conhecimento o que fica oculto são relações de saber-poder. Uma das sustentações da verdade-conhecimento é o fato de que a partir da modernidade ela passa a ser uma verdade aceita como universal e hegemônica, tendo assim o poder para determinar o que é verdadeiro e o que é falso.

Foucault (2006) destaca que é o conjunto das práticas discursivas que faz alguma coisa entrar "no jogo do verdadeiro e do falso e o constitui como objeto para o pensamento seja sob a forma de reflexão moral, do conhecimento científico, da análise política etc." (FOUCAULT, 2006, p. 242).

São estes conjuntos de práticas discursivas que fazem com que determinadas formas 
de saberes sejam consideradas verdadeiras e outras não. É desta forma que o discurso científico se qualifica como verdadeiro, mascarando a vontade de verdade e as relações de poder que o perpassam e na relação antinômica com os outros discursos, ao mesmo tempo em que exclui o outro como falso, se instaura como verdadeiro.

A vontade de verdade presente no discurso científico tende a exercer sobre os outros discursos "uma espécie de pressão e como que um poder de coerção" (FOUCAULT, 1999, p. 18). Essa vontade de verdade da qual pouco se fala se oculta por trás do discurso científico “como se para nós a vontade de verdade e suas peripécias fossem mascaradas pela própria verdade em seu desenrolar necessário" (FOUCAULT, 1999, p. 19-20).

Como essa vontade de verdade e esse poder coercivo se ocultam por trás dos discursos oficiais, o que aparece aos nossos olhos é uma verdade que "seria riqueza, fecundidade, força doce e insidiosamente universal". Por outro lado, deixamos de ver a vontade de verdade, "como prodigiosa maquinaria destinada a excluir todos aqueles que, ponto por ponto, em nossa história, procuraram contornar essa vontade de verdade e recolocála em questão contra a verdade" (FOUCAULT, 1999, p. 20-21).

Para encontrarem-se "no verdadeiro" as verdades dos discursos científicos, precisam situar-se num plano de exigências complexas e pesadas.

\begin{abstract}
$\mathrm{Na}$ história das ciências, não se pode conceber a verdade como adquirida, mas tampouco se pode fazer a economia de uma relação com o verdadeiro e da oposição do verdadeiro e do falso. É essa referência à ordem do verdadeiro e do falso que dá a essa história sua especificidade e sua importância. De que forma? Concebendo que ela se relaciona com a história dos "discursos verídicos", ou seja, com os discursos que se retificam, se corrigem e que operam em si mesmos todo um trabalho de elaboração finalizada pela tarefa do "dizer verdadeiro". [...] O erro não é eliminado pela força surda de uma verdade que, pouco a pouco, sairia da sombra, mas pela formação de uma nova forma de "dizer verdadeiro" (FOUCAULT, 2008, p. 359).
\end{abstract}

As grandes transformações científicas e as grandes descobertas podem ser lidas como o surgimento de novas formas na vontade de verdade a partir de certas relações de poder (FOUCAULT, 1999, p. 16-17).

O discurso científico opera, portanto, numa relação muito próxima entre poder e saber, ao mesmo tempo em que busca, a todo momento, fazer desaparecer o acontecimento e o acaso.

Foucault (1999, p. 35) considera que não somos capazes de "nos encontramos no verdadeiro senão obedecendo às regras de uma 'polícia' discursiva que devemos reativar em cada um de nossos discursos”. Pode-se dizer que esta polícia discursiva tem por objetivo preservar o horizonte teórico de determinada ciência e, ao mesmo tempo, numa determinada época, desqualificar os outros saberes. 
Sobre este ponto, Nietzsche (1987, p.99) afirma que

[...] o cientista constrói a sua cabana junto à torre da ciência para poder ajudá-la e para encontrar proteção para si próprio. E necessita desta proteção, porque existem forças temíveis que continuamente exercem pressão sobre ele e que opõem à "verdade" científica, "verdades" de uma espécie totalmente diferente, dos tipos mais heterogêneos.

Uma pertinente metáfora sobre o discurso científico moderno e a verdade nos é fornecida por Castro-Gómez (2005) em seu livro intitulado La hybris del punto cero.

Para o autor, são poucos os indivíduos qualificados a descobrir a verdade científica, esses sujeitos universais localizam-se no que o autor denomina de imaginário eurocêntrico do ponto zero. O ponto zero é o imaginário segundo o qual um observador se coloca em uma plataforma de observação completamente neutra de onde é capaz de observar tudo ao mesmo tempo em que não pode ser observado de nenhum ponto (CASTRO-GÓMEZ, 2005, p. 18).

A partir deste ponto zero, é possível colocar em circulação um discurso neutro, capaz de instituir quais conhecimentos são verdadeiros e quais são falsos. Isto é possível, uma vez que se acredita que no ponto zero se está alheio a quaisquer interferências externas e relações de poder, não contaminando assim o observador com preconceitos, pré-concepções etc.

Localizar-se no ponto zero equivale a ter o poder de instituir, de representar, de construir uma visão sobre o mundo social e natural reconhecida como legítima e autorizada pelo Estado. Trata-se de uma representação na qual os "varões ilustrados" se definem a si mesmos como observadores neutros e imparciais da realidade (CASTRO-GÓMEZ, 2005, p. 25).

Este imaginário do ponto zero do conhecimento, como nos apresenta Castro-Gómez, e a linguagem científica estão fortemente entrelaçados. Este entrelaçamento se dá pela linguagem científica, pois é ela que possibilita o ocultamento do sujeito concreto e localizado possibilitando assim uma universalização do sujeito abstrato.

Essa verdade posta em circulação a partir de um ponto zero de observação, proferida por um sujeito concreto que se autointitula universal por meio da linguagem científica, pode então passar a ser considerada como a mais perfeita forma de conhecimento. Assim, acreditase ser possível que a ciência, através de sua linguagem exata, abstrata e neutra, seja capaz de produzir um conhecimento também exato, abstrato e neutro sobre o mundo natural e social. Pelas características da obtenção deste conhecimento ele é assumido como isento de erro, de parcialidade, como sendo atemporal, universal e completamente alheio às relações de poder que permeiam os discursos e a sociedade.

Uma verdade matemática provada na Grécia há 24 séculos continuará válida por toda a eternidade, na Terra, em Marte ou em qualquer outro local do universo (GARBI, 2010, p. 20). 
O lugar real de onde o discurso das ciências é proferido começa a se tornar irrelevante no momento que surge uma ideia de ciência rigorosa, mais precisamente com Galileu e Descartes, onde qualquer observador pode valer-se de um telescópio e da linguagem matemática ou reconstruir os passos solipsistas que levam à verdade.

Descartes foi o pensador que melhor deixou transparecer a pretensão "de que a sociedade pode ser observada de um lugar neutro de observação não contaminado pelas contingências relativas ao espaço e ao tempo" (CASTRO-GÓMEZ, 2005, p.24).

Ainda segundo Castro-Gómez (2005), Descartes coloca que só é possível atingir a verdade no conhecimento científico se o observador se desvencilhar previamente de todo conhecimento advindo do senso comum. Somente assim é possível encontrar um ponto sólido de partida para a construção do edifício do conhecimento. Este distanciamento se faz necessário porque "a causa principal dos erros na ciência proveem da excessiva familiaridade que tem o observador com seu meio social e cultural" (CASTRO-GÓMEZ, 2005, p. 25).

Podemos perceber também na história do desenvolvimento do que convencionamos chamar hoje de Matemática algo muito similar a este desejo cartesiano. No início do desenvolvimento da teoria de conjuntos, matemáticos como Zermelo, Fraenkel e Skolem, propuseram que a construção teórica deveria ser feita sobre uma base axiomática o mais restrita possível com o objetivo de eliminar e não permitir quaisquer erros, principalmente os advindos de fora da linguagem matemática (EVES, 2008, 675).

Em outras palavras, buscou-se um banimento do uso da linguagem corrente na construção do conhecimento matemático, evitando assim interferências que pudessem dar margem a ambiguidades e contradições, dando assim uma ênfase cada vez maior a linguagem matemática (DAMÁZIO JÚNIOR, 2015, p. 57).

A linguagem e o método científico assumem um destaque e uma importância tão grandes que se imagina ser o fundamento de todos os campos do conhecimento.

Em Descartes, como se sabe, a objetividade da ciência provém de um método em que se busca na mente uma certeza primária (ideias "claras e distintas") para depois, e de forma estritamente matemática, deduzir dela todas as verdades científicas (CASTRO-GÓMEZ, 2005, p. 26)

Com Descartes funda-se a ideia de que através de uma linguagem e de um método seja possível afastar do sujeito tudo aquilo que possa atrapalhar o seu acesso à verdade, pois se trata de "um método puramente 'racional', baseado no exercício pleno da razão humana" (MONTOITO; GARNICA, 2014, p. 108). Assim, é possível ao homem da ciência e observador do mundo natural e social ficar ausente de seu próprio discurso e eliminar sua localização, se deixando ser um sujeito concreto, localmente situado, e transformando-se num sujeito abstrato. 
É esse o método e o remédio cartesiano. O método, ou seja, a via que conduz à verdade. É o remédio que nos cura da indecisão e da dúvida. Precisamos nos desfazer de todas as ideias, de todas as crenças recebidas, ou seja, libertarmo-nos de todas as tradições, de todas as autoridades, se quisermos uma vez reencontrar a pureza nativa da nossa razão, chegar à certeza da verdade (KOYRÉ apud MONTOITO; GARNICA, 2014, p. 107).

Nietzsche e Foucault expõem a ilusão da ideia de um sujeito universal e abstrato. Nietzsche (2004, p.109) fala do "puro sujeito do conhecimento, isento de vontade, alheio à dor e ao tempo", chamando a atenção para a fábula desse "sujeito universal".

\begin{abstract}
De agora em diante, senhores filósofos, guardemo-nos bem contra a antiga, perigosa fábula conceitual que estabelece um "puro sujeito do conhecimento, isento de vontade, alheio à dor e ao tempo", guardemo-nos dos tentáculos de conceitos contraditórios como "razão pura", "espiritualidade absoluta", "conhecimento em si" - tudo isso pede que se imagine um olho que não pode absolutamente ser imaginado, um olho voltado para nenhuma direção, no qual as forças ativas e interpretativas, as que fazem com que ver seja ver-algo, devem estar imobilizadas, ausentes; exige-se do olho, portanto, algo absurdo e sem sentido. Existe apenas uma visão perspectiva, apenas um conhecer perspectivo (NIETZSCHE, 2004, p. 109).
\end{abstract}

Ainda sobre este ponto, Nietzsche destaca que

"Pensa-se: por conseguinte, existe pensante" - a isso tende a argumentação de Descartes, mas isso equivale a colocar nossa crença no conceito de substância como "verdade a priori": - que, quando se pensa, deva existir algo "que pensa" é apenas uma formulação do nosso hábito gramatical, que põe um autor para um fazer. Em resumo, aqui um postulado lógico-metafísico é criado - e não somente constatado... Pela via de Descartes, não se chega a algo absolutamente certo, mas apenas ao fato de uma crença muito forte (NIETZSCHE apud MARTON, 2000, p. 19).

Para Foucault (1999) não é o sujeito sem espaço e tempo que determina a verdade, mas justamente o espaço, permeado por discursos, onde o sujeito se encontra.

\title{
2 Ideologia da certeza matemática
}

Essa concepção de verdade como verdade-conhecimento se manifesta, como vimos, na Matemática e, consequentemente, também repercute no ensino de Matemática de diversas formas. Destacaremos as reflexões referentes a uma destas manifestações, conhecida como Ideologia da Certeza Matemática.

É importante destacar que não estamos usando, neste texto, certeza e verdade como sinônimos, muito menos o conceito de verdade-conhecimento como sinônimo de ideologia da certeza. A discussão a respeito da verdade é uma questão de fundo altamente filosófico, no qual se busca compreender quais são algumas possíveis fontes históricas e genealógicas que possibilitaram que o discurso científico e matemático se impusessem como hegemônicos sobre outras formas de saber. 
Neste sentido, a Ideologia da Certeza Matemática é um produto deste imaginário da modernidade, só sendo possível de ser posto em circulação por conta da autossustentada crença de que o conhecimento matemático é um conhecimento verdadeiro, proveniente de um lugar neutro e atemporal, conforme discutido anteriormente.

Uma definição de Ideologia da Certeza é apresentada por Borba (1992), e está associada à ideia de que a Matemática está presente em diversas situações cotidianas, sendo usada para comprovar pontos de vistas e reafirmar opiniões. O poder da Matemática de conter o argumento definitivo está relacionado ao que se denomina Ideologia da Certeza (BORBA, 1992).

Isso ocorre porque, desde muito jovens, aprendemos a confiar sem qualquer distinção em dados numéricos, a acreditar que a prova numérica confere exatidão, a crer que os números sempre dizem a verdade (PINHEIRO, 2005, p. 15).

Nesses termos, Borba e Skovsmose (2001) consideraram duas ideias como bases da Ideologia da Certeza:

1) A matemática é perfeita, pura e geral, no sentido de que a verdade de uma declaração matemática não se fia em nenhuma investigação empírica. A verdade matemática não pode ser influenciada por nenhum interesse social, político ou ideológico.

2) A matemática é relevante e confiável, porque pode ser aplicada a todos os tipos de problemas reais. A aplicação da matemática não tem limite, já que é sempre possível matematizar um problema (BORBA; SKOVSMOSE, 2001, p. 130).

É possível identificar, em cada uma dessas ideias, problemas de compatibilidade com a realidade. A primeira ideia afirma uma pureza e generalidade do conhecimento matemático. Para Skovsmose,

\begin{abstract}
filósofos da matemática têm ficado obcecados com a noção de certeza. Acreditam que, por meio da matemática, a possibilidade de obter certeza de conhecimento tem sido demonstrada. Reconheceu-se que essa certeza cresceu nas várias definições de conhecimento, significando que conhecimento pode ser obtido em áreas onde a certeza fosse possível. Dessa forma, se uma afirmação pode ser posta em dúvida, não seria incluída no estoque de conhecimento. Não surpreende, então, que isso se transforme em uma obsessão para entender a natureza da certeza obtida com a matemática, na medida em que isso forneceu um modelo geral para a construção do conhecimento (SKOVSMOSE, 2007, p. 182).
\end{abstract}

Esta ideia de conhecimento único e verdadeiro, de generalização, advêm, diretamente, de uma das características da Ciência Moderna: reduzir o universo a dados quantitativos. Desta forma, a Ciência Moderna e seu imaginário do ponto zero, viu na Matemática a ferramenta perfeita para tal.

Deste lugar central da matemática na ciência moderna derivam duas consequências principais. Em primeiro lugar, conhecer significa quantificar. O rigor científico afere-se pelo rigor das medições. As qualidades intrínsecas do objecto são, por assim dizer, desqualificadas e em seu lugar passam a imperar as quantidades em que 
eventualmente se podem traduzir. O que não é quantificável é cientificamente irrelevante. Em segundo lugar, o método científico assenta na redução da complexidade. O mundo é complicado e a mente humana não o pode compreender completamente. Conhecer significa dividir e classificar para depois poder determinar relações sistemáticas entre o que se separou (SANTOS, 2009, p. 27).

Sobre a primeira ideia que dá base para a ideologia da certeza, de que é um conhecimento puro, podemos nos questionar acerca da neutralidade da Matemática como conhecimento. Afinal, como escreve Bazzo (2014, p. 149), “[...] a ciência é uma atividade social, estando sujeita à mudanças estruturais, à variações e, sem dúvida alguma, permanecendo atrelada a uma infinidade de outros interesses".

Nietzsche (1983, p.45) coloca que "[...] havia uma vez um astro, em que animais inteligentes inventaram o conhecimento", ou seja, para o autor, o conhecimento não passa de uma criação humana. Assim, como criação humana, está sujeito à influências de diversos fatores, como influências políticas, religiosas e culturais. Devido ao fato de o conhecimento (podemos substituir aqui o conhecimento por a verdade) ser criação humana, estes mesmos são mutáveis, “[...] não existem fatos eternos, assim como não existem verdades absolutas" (NIETZSCHE, 2005, p. 11).

A segunda ideia base da ideologia da certeza, que considera a Matemática como sendo aplicável em todas as situações, também pode ser problematizada.

Segundo Skovsmose (2007)

É uma ilusão pensar que aplicações da matemática tragam soluções, com fidedignidade garantida, mediante o uso da matemática. A ideologia da certeza torna-se problemática quando opera fora da sala de aula de matemática, ao tratarmos (de forma real) com compras, preços, dinheiro, pagamento, taxas de câmbio, velocidade, aceleração, distância, etc. (SKOVSMOSE, 2007, p. 83).

Alguns problemas de aparente fácil solução matemática, se analisados com mais atenção, mostram que muitos outros fatores, além dos puramente quantitativos devem ser levados em consideração. Borba e Skovsmose (2001) apresentam um exemplo de como uma solução puramente matemática pode não ser a mais adequada.

\footnotetext{
Os distritos A, B e C têm, respectivamente, as populações 50 mil, 20 mil e 10 mil habitantes. Cada distrito elege um representante com o mesmo poder para a Câmara de Deputados de Saint Lawrence. Muitas pessoas, de diferentes distritos, reclamaram dessa situação; elas acham que não é justa. Quantos representantes cada distrito deve ter se o número total de representantes deve ser mantido em um mínimo? (SKOVSMOSE; BORBA, 2001, p. 140).
}

Segundo os autores, os alunos tendem a responder a questão usando proporção simples, considerando a questão de fácil resolução. A resposta dada é que devem existir 5 representantes do distrito A, 2 do B e 1 do C. Entretanto, nessa disposição, o distrito A sempre decidiria todas as questões políticas. Essa resposta não é satisfatória, pois deixa de lado 
diversos fatores relevantes que precisam ser considerados no problema real.

Sempre se acreditou que a ciência e a tecnologia eram supremas e únicas para a resolução de todos os problemas. Acreditou-se nesse paradigma até muito recentemente, mas agora se sabe que elas não os resolvem sozinhas. Existe um entorno determinado pelo comportamento social que define, e mais do que isso, impõe esses benefícios (BAZZO, 2014, p. 168).

É frequente também o uso de argumentos matemáticos na televisão e em outras mídias, utilizando de diversos números, porcentagens, tabelas etc. que servem como argumentação para comprovar um ponto. A Matemática é apresentada como um medidor da realidade. Nas palavras de Borba e Skovsmose, pode-se dizer que

[...] é essa a visão usada pelos programas de televisão sobre ciências, pelos jornais, pelas escolas e universidades. Nesses ambientes, a matemática é frequentemente retratada como instrumento/estrutura estável e inquestionável em um mundo muito instável. Frases como "foi provado matematicamente", "os números expressam a verdade", "os números falam por si mesmos", "as equações mostram/asseguram que" são frequentemente usadas na mídia e nas escolas. Essas frases parecem expressar a matemática como uma referência "acima de tudo", como um "juiz", que está acima dos seres humanos, como um artifício não humano que pudesse controlar a imperfeição humana (SKOVSMOSE; BORBA, 2001, p. 129).

Essa concepção da Matemática traz uma ideia de que ela é algo bonito e perfeito, do qual sempre podemos retirar respostas verdadeiras e confiáveis. Diante disso, é plausível pensar que esta ideologia se faz presente também nas escolas, que circula pelos corredores, atrás das portas, entre as carteiras e nos discursos dos principais atores do processo educativo, professores e alunos.

Esta Matemática herdeira da noção cartesiana de verdade é aquela hoje incorporada aos currículos escolares, tida como a verdadeira e a única a dar conta da realidade na qual vivemos. Mais do que isso, ela é vista como a representação da própria realidade, um seu correlato; isto é, razão e mundo, ou realidade, passam a ser relacionados pela representação (CLARETO; SÁ, 2006, p. 6).

Uma possível forma de se contrapor, ou de oferecer resistência, a esta concepção de Matemática presente nas salas de aula e que se sustenta por sua pretensa universalidade conceitual com origens no imaginário moderno, é problematizando justamente os seus principais fundamentos. Esses fundamentos estão diretamente relacionados às crenças de que a Matemática é "onipresente (contexto neutro), onisciente (a verdade final) e onipotente (ela funciona em todo lugar)" (BORBA, 1992, p. 333).

\section{Considerações finais ou convite a novas formas de olhar}


Ainda que o objetivo principal deste trabalho seja a problematização da questão da verdade e apresentar a Ideologia da Certeza como um exemplo de como a verdade, conforme apresentada anteriormente, pode se manifestar também em Matemática e no ensino de Matemática, consideramos importante apresentar outra concepção de verdade, uma alternativa epistemológica possível.

A este tipo de verdade, Foucault dá o nome de verdade-acontecimento. Foucault apresenta esta concepção de verdade na aula do dia 23/02/1974, num curso proferido no Curso do Collège de France e compilado no livro O Poder Psiquiátrico. Este tipo de verdade não se trata de algo a ser construído, mas sim que já está dada, posta e presente.

Foucault chama a verdade-acontecimento de verdade raio em contraste com a verdade-conhecimento, a verdade céu, que se julga universalmente presente mesmo que encoberta pelas nuvens.

Ao tratar dessas duas noções de verdade, Foucault (2006) destaca que a verdade céu, ou seja, a verdade-conhecimento, encobriu outras formas de verdades descontínuas, dispersas, aleatórias e sem pretensões de generalidade.

\footnotetext{
Eu gostaria de fazer valer a verdade-raio contra a verdade-céu, isto é, mostrar por um lado como essa verdade-demonstração - cuja extensão, cuja força, cujo poder que ela exerce atualmente é absolutamente inútil negar -, como essa verdadedemonstração, identificada, grosso modo, com a prática científica, como essa verdade demonstração deriva na realidade da verdade-ritual, da verdadeacontecimento, da verdade-estratégia, como a verdade-conhecimento no fundo não passa de uma região e de um aspecto que se tornou pletórico, que adquiriu dimensões gigantescas, mas um aspecto ou uma modalidade, mais uma vez, da verdade como acontecimento e da tecnologia dessa verdade-acontecimento (FOUCAULT, 2006, p. 305).
}

Para Foucault (1998), o acontecimento é a irrupção de uma singularidade única e aguda, que se dá no lugar e no momento de sua produção. Foucault destaca ainda que "há toda uma tradição da história (teleológica ou racionalista) que tende a dissolver o acontecimento singular em uma continuidade ideal - movimento teleológico ou encadeamento natural" (FOUCAULT, 2005, p. 28).

Nesse sentido, é possível questionar a crença, tão presente em Matemática, na existência de uma verdade que está à espera de ser descoberta. Diferente da verdadeconhecimento, a verdade-acontecimento é dispersa, descontínua, localizada e particular. Ela só fala ou se produz em determinado lugar, é uma verdade que não se produz a todo o tempo, nem para todo o mundo. Não é uma verdade que nos espera, mas é uma verdade que tem instantes favoráveis, lugares propícios, agentes e seus portadores privilegiados (FOUCAULT, 2006, p. 303). 
A verdade-acontecimento não é uma verdade atingida por métodos, caminhos conhecidos ou emprego da razão. É uma verdade que anda de mãos dadas com o imprevisto e com a liberdade.

\begin{abstract}
Quem alcançou em alguma medida a liberdade da razão, não pode se sentir mais que um andarilho sobre a Terra - e não um viajante que se dirige a uma meta final: pois esta não existe. Mas ele observará e terá olhos abertos para tudo quanto realmente sucede no mundo; por isso não pode atrelar o coração com muita firmeza a nada em particular; nele deve existir algo de errante, que tenha alegria na mudança e na passagem (NIETZSCHE, 2005, p. 271).
\end{abstract}

São justamente essas características incertas, que se apresentavam como acontecimentos dispersos, como "decisões, acidentes, iniciativas, descobertas" o que o imaginário da ciência moderna e da Matemática baniu para terras distantes ou se esforça para esconder debaixo do tapete. Essas características precisavam ser apagadas para que uma racionalidade, de tipo cartesiana, e uma continuidade, mesmo que ilusória, pudessem aparecer (FOUCAULT, 1995, p. 9).

Trata-se, portanto, de uma verdade que tem sua geografia e sua cronologia, ela tem um kairos, ou seja, está ligada a ocasião em que se deve aproveitar a oportunidade, o tempo de ação possível. "Essa verdade com sua geografia, seus calendários, seus mensageiros ou seus operadores privilegiados, não é universal”. Isso não significa que seja uma verdade rara, mas uma verdade dispersa que se produz assim como um acontecimento (FOUCAULT, 2006, p. 304).

Inevitavelmente a escola e as relações de ensino são influenciadas, se não frutos diretos, dessa racionalidade que se instaura como verdadeira representação do mundo. A Matemática na aula de Matemática é aquela de natureza eterna, atemporal e, por isso, independe da existência dos professores e alunos envolvidos no processo.

A escola vem sendo pensada, organizada e vivenciada baseando-se muito fundamentalmente na racionalidade cartesiana. Tanto a organização de seus espaços e tempos, quanto a constituição dos saberes escolares têm, na razão cartesiana, seus modelos. Assim, os currículos seguem o "modelo da escada", ou seja, com prérequisitações baseadas na lógica "do mais simples ao mais composto". Além disso, a busca por verdades e a total dicotomização entre certo e errado, verdadeiro e falso, processos "mais elegantes" e "menos elegantes", algoritmos "mais fáceis" e "mais difíceis” dominam as constituições de currículos escolares (CLARETO; SÁ, 2006, p. 11).

Operar fora desta concepção de verdade constitui um desafio para sociedade, escola, professores e alunos. Primeiramente se faz necessário compreender e problematizar a concepção de Matemática como saber privilegiado e "como constituidora da racionalidade moderna que tem sido o fio que tece a educação escolar" (CLARETO; SÁ, 2006, p. 1). Perceber isso tem o potencial de afrouxar um pouco as amarras discursivas que circulam no 
meio escolar e nas aulas de Matemática, como a ideologia da certeza.

Cada escola, cada sala de aula, cada aluno e cada aula apresenta uma riqueza de verdades e acontecimentos únicos, que não dependem apenas da visão da Matemática como verdade-conhecimento. Trata-se apenas de perceber, abrir os olhos e dar sentido e valor à riqueza que existe além do valorizado pelo discurso epistemológico dominante. Não se trata nem de abandonar ou lutar contra a presença desses elementos na aula de Matemática ou em nossas posturas, mas de perceber, permitir e valorizar outros elementos que estão continuamente ocorrendo simultaneamente por trás dos discursos.

\begin{abstract}
A sala de aula como acontecimento. A matemática como acontecimento na sala de aula. Que matemática acontece na sala de aula? Que aula acontece? Abrir-se ao intempestivo, ao imprevisto e ao imprevisível. Abertura que racha a forma-sala-deaula-de-matemática - plano composto por forma-aluno, forma-professor, formaconteúdo, forma-matemática, forma-livro didático... - em sua previsibilidade, em seu planejamento, em seus mecanismos de controle, em sua forma já capturada e esquadrinhada. A aula acontece! Que aula acontece? (CLARETO, 2013, p. 3).
\end{abstract}

Em cada escola, em cada sala de aula, encontram-se diferentes indivíduos, cada um com aspectos subjetivos, que não podem ser quantificados. É simples que se saiba a altura, o peso de um aluno ou até mesmo a média de idade de cada turma. Entretanto, mais útil para o ensino seria entender pelo que se interessam, o que está exercendo influência sobre eles e que questões sociais estão interferindo em seu cotidiano. Na Educação Matemática - e na Educação como um todo - não é ideal considerar apenas o quantitativo.

O rigor científico, porque fundado no rigor matemático, é um rigor que quantifica e que, ao quantificar, desqualifica, um rigor que, ao objectivar os fenómenos, os objectualiza e os degrada, que, ao caracterizar os fenómenos, os caricaturiza. [...] Nestes termos, o conhecimento ganha em rigor o que perde em riqueza e a retumbância dos êxitos da intervenção tecnológica esconde os limites da nossa compreensão do mundo e reprime a pergunta pelo valor humano do afã científico assim concebido (SANTOS, 2009, p. 54).

O desafio educacional que se apresenta não é, portanto, necessariamente fundar algo novo, revolucionar ou subverter a aula de Matemática, mas perceber o que já está presente nas aulas, todo um rico universo que, por exemplo, a ideologia da certeza matemática se esforça por ocultar, desvalorizar e categorizar como irrelevante, se não prejudicial ao processo de ensino.

\title{
Referências
}

BAZZO, W. A. Ciência, tecnologia e sociedade e o contexto da educação tecnológica. 1. ed. Florianópolis: Editora da UFSC, 2014.

BORBA, M. de C. Challenging the sacred cow of mathematical certainty. The Clearing House, Philadelphia, v. 65, n. 6, p. 332-333, 1992. 
BORBA, M. de C.; SKOVSMOSE, O. A ideologia da certeza em educação matemática. In: SKOVSMOSE, O. Educação matemática crítica: a questão de democracia. Campinas: Papirus, 2001. p. 127-148.

CASTRO-GÓMEZ, S. La hybris del punto cero. Ciencia, raza e ilustración en la Nueva Granada (1750-1816). 1. ed. Bogotá: Pontificia Universidad Javeriana, 2005.

CLARETO, S. M. Matemática como acontecimento na sala de aula. In: REUNIÃO NACIONAL DA ANPED (Sistema Nacional de Educação e Participação Popular: Desafios para as Políticas Educacionais), 36. 2013, Goiânia. Anais...Goiânia: UFG, 2013. Disponível em: <http://36reuniao.anped.org.br/trabalhos/177-trabalhos-gt19-educacao-matematica>. Acesso em: 06 set. 2017.

CLARETO, S. M.; SÁ, É. A. de. Matemática e educação escolar: lugares da matemática na escola e possibilidades de ruptura. In: REUNIÃO ANUAL DA ANPED - EDUCAÇÃO, CULTURA E CONHECIMENTO NA CONTEMPORANEIDADE, 29., 2006, Caxambu. Anais... Caxambu: ANPED, 2006. Disponível em: <http://29reuniao.anped.org.br/trabalhos/trabalho/GT19-2283-Int.pdf>. Acesso em: 05 set. 2017.

DAMÁZIO JÚNIOR, V. Metáforas, Aforismos e Reflexões: Aproximações entre Matemática, Educação Matemática e Arte. BoEM, Joinville, v. 3. n. 5, p. 51-68, ago./dez. 2015.

DESCARTES, R. Discurso do Método. Trad. De Roberto Leal Ferreira. 2. ed. São Paulo: Martin Claret, 2009.

EVES, H. W. Introdução à história da matemática. 1. ed. São Paulo: Ed. da UNICAMP, 2008.

FOUCAULT, M. A arqueologia do saber. Trad. de Luiz Felipe Baeta Neves. 4. ed. Rio de Janeiro: Forense Universitaria, 1995.

FOUCAUlT, M. A ordem do discurso. Trad. de Laura Fraga de Almeida Sampaio. 5. ed. São Paulo: Loyola, 1999.

FOUCAULT, M. Microfísica do poder. 21. ed. Rio de Janeiro: Graal, 2005.

FOUCAULT, M. O poder psiquiátrico. Curso do Collège de France (1973-1974). Trad. de Eduardo Brandão. 1. ed. São Paulo: Marins Fontes, 2006.

FOUCAULT, M. Segurança, território, população. Curso do Collège de France (1977-1978). Trad. de Eduardo Brandão. 1. ed. São Paulo: Marins Fontes, 2008.

GARBI, G. G. C. Q. D.: explicações e demonstrações sobre conceitos, teoremas e fórmulas essenciais da geometria. 1. ed. São Paulo: Livraria da Física, 2010.

MARTON, S. Nietzsche e Descartes: filosofias de epitáfio. O que nos faz pensar, Rio de Janeiro, v. 11, n. 14, p. 7-23, ago. 2000.

MONTOITO, R.; GARNICA, A. V. M. Ecos de Euclides: breves notas sobre a influência d'Os Elementos a partir de algumas escolas filosóficas. Educação Matemática Pesquisa, São Paulo, v. 16, n. 1, p. 95-123, 2014.

NIETZSCHE, F. Obras incompletas. Trad. de Rubens Rodrigues Torres Filho. 3. ed. São Paulo: Abril. Cultural, 1983. 
NIETZSCHE, F. O livro do filósofo. 1. ed. São Paulo: Moraes, 1987.

NIETZSCHE, F. Genealogia da moral. Trad. de Paulo César de Souza. 1. ed. São Paulo: Companhia das Letras, 2004.

NIETZSCHE, F. Além do Bem e do Mal. Trad. Paulo César de Souza. 1. ed. São Paulo: Companhia das Letras, 2005.

NIETZSCHE, F. Humano, demasiado humano: um livro para espíritos livres. 1. ed. Companhia das letras, São Paulo, 2005.

PINHEIRO, N. A. M. Educação crítico-reflexiva para um ensino médio científico-tecnológico: a contribuição do enfoque CTS para o ensino aprendizagem do conhecimento matemático. 2005. 306 p. Tese (Doutorado em Educação Científica e Tecnológica) - Universidade Federal de Santa Catarina, Centro de Ciências da Educação, 2005.

SANTOS, B. de S. Um discurso sobre a ciência. 6. ed. São Paulo: Cortez, 2009.

SKOVSMOSE, O. Educação Crítica: Incerteza, matemática, responsabilidade. 1. ed. São Paulo: Cortez, 2007.

Submetido em 20 de Abril de 2018. Aprovado em 27 de Setembro de 2018. 